Article

\title{
Assessment of the level and factors associated with knowledge, attitude and practice of blood donation among medical and paramedical personnel in ALERT Hospital, Ethiopia
}

\author{
Malese Yeshambaw Teferi, ${ }^{1}$ Simon Genet Woldesenbet, ${ }^{1}$ Solomon Asnakew Feleke, ${ }^{2}$ \\ Ermias Hundito Abebe, ${ }^{1}$ Hawult Taye Adane, ${ }^{1}$ Chalachew Misganaw Alemayehu ${ }^{1}$ \\ ${ }^{1}$ Armauer Hansen Research Institute (AHRI), Addis Ababa; ${ }^{2}$ World Health Organization, Addis Ababa, Ethiopia
}

\begin{abstract}
Background: Though there was a high blood supply need in response to high communicable disease and increased emergency conditions; the practice of health professionals and non-health professionals on voluntary blood donation is still unexpectedly low in Ethiopia. Health professionals and non-health professionals working in the health sectors are pivotal in taking the lead to reverse the effect of inadequate blood supply system in the country. Therefore, the study aimed to understand the level and contributing factors of knowledge, attitude and practice of voluntary blood donation among health and non-health professionals in ALERT Hospital, Addis Ababa, Ethiopia.

Design and Methods: A cross-sectional study design was conducted among health professionals and non-health professionals in ALERT hospital from 5 to 30 June 2018. A total of 394 hospital staffs participated in this study. A well-structured self-administered questionnaire was used to assess the knowledge, attitude, and practice about voluntary blood donation. The statistical analysis was carried out using $\mathrm{R}$.

Results: A total of $203(51.5 \%)$ participants were females. Only $142(36 \%)$ of the participants had voluntary blood donation practice. Among these, $60(42.3 \%)$ of them were donated blood more than once. Occupation is the only factor significantly associated with blood donation practice; health professionals had almost two-fold donation practice than non-health professionals $(\mathrm{AOR}=1.62 ; 5 \% \mathrm{CI}: 1.02,2.57, \mathrm{p}=0.042)$. Occupation has also a strong relationship with knowledge, health professionals had better knowledge than non-professionals with $(\mathrm{AOR}=2.39$; 95\% CI: $1.39,4.12 ; \mathrm{p}=0.002)$. The result also showed that the educational status of the participants was strongly associated with the blood donors' attitude with $(\mathrm{AOR}=3.62 ; 95 \% \mathrm{CI}: 1.1,11.93, \mathrm{p}=0.035)$. One hundred and two $(72.3 \%)$ of the blood donors were motivated to donate blood for charity, $133(94.3 \%)$ individuals were felt good after blood donation and lack of request was the major rea-
\end{abstract}

son $88.6 \%$ that causes the respondents not to donate blood frequently.

Conclusions: Low blood donation practice of health professionals and non-health professionals was identified from this study. Occupation had significantly associated with blood donation practice. Therefore, targeted interventions aimed at mobilizing hospital staffs and develop accessible blood donation centers are recommended to reverse the effect of inadequate blood supply system in Ethiopia.

\section{Introduction}

Blood can only be given from generous donors. ${ }^{1}$ Blood donation is necessary to maintain an adequate supply of blood to patients who are suffering from any kind of disease or trauma, which requires them to have a blood transfusion. ${ }^{2}$ Currently, there are no global standards used to estimate the national requirements for blood and blood products. The need for blood and blood products is dynamic and is dependent upon health service coverage, the level of health care system and the hospital blood usage. The current levels of blood collection in low-income countries have been limited to cover the blood requirements of their health care systems. ${ }^{3}$ Disproportionately low percentages of the population in Low and Middle-Income Countries (LMICs) donates blood, and rapidly increasing demand due to improved access to healthcare in some LMIC directly contributes to the gap between blood supply and demand. ${ }^{4}$

According to the WHO Global Status Report on Blood Safety and availability, the African Region collected a total of about 5.6 million blood donations; these accounted for only about $4 \%$ of global donations. ${ }^{3}$ The unpublished data from United Nations Office for Drug and crime stated that "the Ethiopian National Blood Bank collects nearly 200,000 units of blood from donors annually. Though, the country requires 18,000 units of blood daily,

Significance for public health

Health professionals and non-health professionals working in the health sector are pivotal in taking the lead so as to reverse the effect inadequate and unsafe blood supply system in the country. The reasons for this fact are these groups of population are likely to be informed of the necessity of blood to manage disease or problems of some patients and know more regarding the safety, risk and procedures of blood donation. Moreover, front line managers who can deal with the shortage and safety related issues especially in an emergency situation. Together with other concerned bodies, they are the one who should influence their family, the community around, and the students. However, only few percentages of individuals from this sector come forward to donate blood on a regular basis. Therefore, the main aim of this research was to understand the level and various factors contributing to knowledge, attitude and practice of voluntary blood donation among medical and paramedical personnel in the health sector. 
yet the average daily amount collected is approximately 1,100 units a shortfall of 16,900 pints". This data is supported by a study conducted in Ethiopia that blood provision is significantly inadequate in a low and middle-income countries like Ethiopia. ${ }^{5}$

A systematic review in Sub Saharan Africa (SSA) described hat pro-social motivation which is the desire to have a positive effect on others or a community, negative attitudes and perceived negative health effects caused by blood donation were most frequently mentioned reasons for poor blood denotation. ${ }^{6}$ In response to this a scoping review of evidence conducted in Sub-Saharan Africa by 2017 support the need for targeted, culturally sensitive education, recruitment and retention strategies to improve the blood supply. ${ }^{7}$ A study conducted among graduating undergraduate health science students at the University of Gondar shows $48.2 \%$ of the participants had adequate knowledge blood donation. ${ }^{8}$ Similarly a study in the eastern part of Ethiopia identified that comprehensive knowledge of the participants toward voluntary blood donation was $43.5 \%$ which is lower than the result of studies conducted in other parts of Ethiopia. ${ }^{9}$ However, in two community-based studies conducted in Ethiopia the blood donation knowledge of the participants were $56.5 \%$ and $56.8 \%$, respectively. ${ }^{10,11} \mathrm{~A}$ study among University students in Iran, in 2018 stated that study participants had $23.6 \%$ negative, $58.7 \%$ moderate, and only $17.7 \%$ good attitude towards blood donation. ${ }^{12}$ Similarly, communitybased studies from Ethiopia found $52.2 \%$ and $32.9 \%$ of favorable attitude towards blood donation. ${ }^{9,11}$ However, a study conducted at Gondar town Northwest Ethiopia in 2016 identified 82\% good attitude towards blood donation, which had huge difference from other similar studies. ${ }^{10}$

Recent studies conducted among health professionals in Ethiopia reported $47.8 \%, 33.2 \%$ and only $21.6 \%$ of the respondents were found to practice blood donation. ${ }^{1,13,14}$ Most commonly reported reasons for low level of blood donation practice were, shortage of time to donate blood, and fear of anemia. ${ }^{15-17}$ Studies conducted in countries from 2014-2018 also stated that, difficulty in accessing blood donation center were the deterrent factor for blood donation. ${ }^{2,15,16,18}$ The recent findings in Ethiopia also stated that health professionals' knowledge and attitude towards blood donation were the predictive factor of voluntary blood donation. ${ }^{13,14}$ Research findings from Ethiopia and Tanzania also reported that lack of education as a key reason for not donating blood. ${ }^{11,13,19}$ Not approving the participant to donate blood was also reported by a recent study from Ethiopia. ${ }^{1}$

Health professionals and non-health professionals working in the health sector are pivotal in taking the lead to reverse the effect of inadequate and unsafe blood supply system in the country. The reasons for this fact are that these groups of population are likely to be informed of the necessity of blood to manage disease or problems of some patients and know more regarding the safety, risk and procedures of blood donation. Moreover, front line managers who can deal with the shortage and safety related issues especially in an emergency situation. Together with other concerned bodies, they are the one who should influence their family, the community around, and the students donate blood. However, in Ethiopia only few percentages of individuals from this sector come forward to donate blood on a regular basis. ${ }^{1,13,14}$ Therefore, the main aim of this research was to understand the level and various factors contributing to knowledge, attitude and practice of voluntary blood donation among medical and paramedical personnel in the health sector.

\section{Methods and Patients}

\section{Study design and area}

A cross-sectional study design was conducted among health professionals and non-health professionals from 5 to 30 June 2018 in the "Africa Leprosy Rehabilitation and Training Center" (ALERT) hospital; ALERT is a medical facility on the edge of Addis Ababa, specializing in Hansen's disease, also known as "leprosy". It was originally the "All Africa Leprosy Rehabilitation and Training Center" (hence the acronym), but the official name is now expanded to include tuberculosis: All Africa Leprosy, Tuberculosis and Rehabilitation Training Centre Addis Ababa, Ethiopia. ALERT hospital was initially established to provide service for leprosy patients; since July 2002, ALERT has modified its activities investing as a tertiary referral and teaching hospital for leprosy and skin diseases under the administration of the Ministry of Health of the Federal Democratic Republic of Ethiopia. Its main current mission is based on provision of quality service and Training Center for Leprosy, Rehabilitation, Surgery, Tropical dermatology, Ophthalmology and relevant infectious diseases. In total, 556 paramedical personnel and 1,000 Medical staffs were working in the hospital.

\section{Study population, sample size, and sampling procedures}

The source population was all paramedical and medical personals who are working in the hospital. Staffs who are not directly linked from the hospital (any staff member working for Armauer Hansen Research Institute (AHRI) and Training Center, which was part of the hospital, currently working independently under the Ministry of Health as Research Institute and Training Center), those who were seriously sick during the data collection period or those who were not around for different academic or personal purposes were excluded from the study. The sample size was determined by using EPI-INFO statcalc for cross-sectional design. Due to absence of related data on this specific subject, the sample size was calculated by considering prevalence of $50 \%$ for maximum sample size and 5\% error with 1.96 significant levels. The total sample size required becomes 384 . Considering 5\% non-response rate, the final sample size determined was 402 . Stratified sampling method was used to have a representative and adequate sample size for each group of the study population. The study population was stratified in to Paramedical and Medical professionals. A separate sample size was developed independently from each stratum by calculating the proportion form a total population in each group, 247 samples from medical and 137 samples from the paramedical section. Then systematic sampling technique was used to select study subjects among the two groups. The sampling interval four (4) was determined for both groups by dividing the number of units in the population by calculated sample size. The first number was selected between one and 4, and one participant was selected in every four (4) units to end up with estimated sample size.

\section{Operational definitions}

Level of knowledge: This is the understanding level of health care workers on blood donation.

Attitude: Attitude is the intention of respondents of the study towards the blood donation practice.

Practice: Practice towards blood donation denotes an experience whether an individual participant had experienced blood donation at least once in a lifetime or not at all. 
Medical personnel: Is health professional that provides preventive, curative, promotional or rehabilitative health care services, who are serving ALERT Hospital.

Paramedical personnel: All non-medical professional who were working in ALERT Hospital.

\section{Measuring of knowledge, attitude, and practice}

Level of knowledge: Knowledge was assessed by 20 questions. Respondents with all correct response got a maximum of 11 points, higher points indicate good knowledge. Based on the total score, knowledge level on blood donation was categorized into poor $(\leq 5$ points), average (6-8 points) and good ( $\geq 9$ points).

Attitude: The attitude for blood donation was assessed through six questions with 'yes' and 'no' options. Those who score less than 3 were categorized as having uncomfortable attitude toward blood donation and those above or equal to 3 were labeled as having comfortable attitude towards blood donation.

Practice: Blood donation practice was categorized as those who ever donate blood, regular donors and those who don't ever donate blood based on their experience of blood donation in one time or regular basis.

\section{Data collection tools and procedures}

A well-structured self-administered questionnaire was used to assess the knowledge, attitude and practice about voluntary blood donation. The questionnaire consists of four sections: Socio-demographic information, practice, knowledge and attitude. Blood donation practice was assessed through seven questions addressing the nature of donation, frequency of donation, reasons for not donating blood etc. Knowledge part contains 20 questions; knowledge on blood donation was assessed through questions covering benefits, requirements and restrictions of blood donation. The attitude for blood donation was assessed through six questions with 'yes' and 'no' options. Pre-test was made on 5\% of the questionnaire (20 questionnaires) AHRI staffs who were not part of the actual study. Following the pre-test, the content of the questionnaires was re-structured based on the feedback from the pre-test exercise. Co-PI's facilitated and coordinated the data collection procedure. The questioner was distributed after detail orientation given by Co-PI's about the objective of the study. Orientation was given when the study participants get in group. Data was collected in two weeks period. Beside to maintain the quality of data, the PI checked the data for completeness and consistency.

\section{Data processing and analysis}

Data was entered; cleaned and coded on SPSS vr.16 and exported to R. Then, the data were analyzed using appropriate descriptive and inferential statistical tests. Logistic regression model was used to predict the knowledge, attitude, and practice. Crude odds ratio (COR) and adjusted odds ratio (AOR) with their $95 \%$ confidence interval $(\mathrm{CI})$ were used to measure the strength of association between dependent and independent variables. A pvalue $<0.05$ was considered for statistical significance for all statistical tests. A scoring mechanism was used to understand overall knowledge level; a score of one was given for each correct response and zero for wrong response. Factor analysis was done to identify factors that explained most of the variance observed in the population with regard to blood donation. A significance level of $\mathrm{p}=0.05$ was taken in all cases.

\section{Results}

\section{Socio-demographic characteristics}

Out of the total 394 study participants, more than half (51.5\%) of them were females. The age of participants ranged from 19 to 60 years with mean age of $33.54(\mathrm{SD}=8.13)$ years. Their income ranges from 1200.00 to 15000.00 with the mean income of 4044.76 ( $\mathrm{SD}=2012.5)$, with 30 Ethiopian birr Dollar exchange rate at the time of data collation. More than half of the participants were married $56.9 \%$ and $59.4 \%$ of them were orthodox followers. Regarding the educational status of study participants, 195 (49.5\%) of them were below Diploma, while the other 199 (50.5\%) of them have Degree and above. A large proportion of the participants $134(34.0 \%)$ were paramedical professionals, followed by nurses 100 (25.4\%) (Table 1).

\section{Socio-demographic factors associated with knowledge}

The knowledge of the participants had ranges from 2 to 10 with mean value of 7.22 ( $\mathrm{SD}=1.56)$. Among the socio-demographic variables, occupation was strongly associated with the blood donation knowledge of the participants. The logistic regression model indicated that health professional had a better knowledge than non-health professionals with $(\mathrm{AOR}=2.39 ; 95 \% \mathrm{CI}: 1.39$, $4.12 ; \mathrm{p}=0.002)$. The likelihood of having favorable knowledge as level of education increase, shown that participants with degree and above level of education were one and half times more likely (AOR=1.5; 95\% CI: 0.9, 2.49) to have blood donation knowledge compared to Diploma level (Table 2).

Table 1. Socio-demographic characteristic of study participants.

\begin{tabular}{|c|c|c|}
\hline Socio-demographic characteristics & Frequency & Percentage \\
\hline $\begin{array}{l}\text { Sex } \\
\quad \text { Male } \\
\quad \text { Female }\end{array}$ & $\begin{array}{l}191 \\
203\end{array}$ & $\begin{array}{l}48.5 \\
51.5\end{array}$ \\
\hline $\begin{array}{l}\text { Age group } \\
\text { less than } 30 \\
30-40 \text { years } \\
40-50 \text { years } \\
\text { Above } 50\end{array}$ & $\begin{array}{l}189 \\
137 \\
55 \\
13\end{array}$ & $\begin{array}{l}48.0 \\
34.8 \\
14.0 \\
3.3 \\
\end{array}$ \\
\hline $\begin{array}{l}\text { Educational status } \\
\text { Below diploma } \\
\text { Degree and above }\end{array}$ & $\begin{array}{l}195 \\
199\end{array}$ & $\begin{array}{l}49.5 \\
50.5\end{array}$ \\
\hline $\begin{array}{l}\text { Occupational status } \\
\text { Paramedical staff } \\
\text { Medical staff } \\
\text { General practitioner } \\
\text { Nurse } \\
\text { Pharmacy } \\
\text { Laboratory } \\
\text { Others* }\end{array}$ & $\begin{array}{c}134 \\
260 \\
58 \\
100 \\
35 \\
42 \\
25\end{array}$ & $\begin{array}{c}34.0 \\
66.0 \\
14.7 \\
25.4 \\
8.9 \\
10.7 \\
6.3\end{array}$ \\
\hline $\begin{array}{l}\text { Religion } \\
\text { Orthodox } \\
\text { Muslim } \\
\text { Protestant } \\
\text { Others }\end{array}$ & $\begin{array}{c}234 \\
59 \\
94 \\
7\end{array}$ & $\begin{array}{c}59.4 \\
15.0 \\
23.9 \\
1.8\end{array}$ \\
\hline $\begin{array}{l}\text { Marital status } \\
\text { Single } \\
\text { Married } \\
\text { Divorced } \\
\text { Widowed } \\
\text { Total }\end{array}$ & $\begin{array}{c}147 \\
224 \\
16 \\
7 \\
394\end{array}$ & $\begin{array}{c}37.31 \\
56.85 \\
4.06 \\
1.78 \\
100.0\end{array}$ \\
\hline
\end{tabular}




\section{Factors associated with attitude}

The only socio-demographic variable that strongly associated with the attitude of blood donors was educational status of the participants. Study participants with degree level of education had three and half time more favorable attitude towards blood donation with $(\mathrm{AOR}=3.62 ; 95 \% \mathrm{CI}: 1.1,11.93), \mathrm{p}=0.035)$ compared to diploma holders. The possibility of favorable attitude towards blood donation among individuals who were 30-40 years $(\mathrm{AOR}=1.3 ; 95 \% \mathrm{CI}: 0.47,3.61)$ and those above 50 years $(\mathrm{AOR}=1.9$; 95\% CI: $0.17,20.83)$ was relatively higher than individuals who were less than 30 years of age. Married $(\mathrm{AOR}=2.54$; 95\% CI: $0.85,7.63)$ and divorced participants (AOR $=3.37$; 95\%CI: $0.29,38.79)$ were more likely to donate blood when compared to the single marital status (Table 3).

\section{Factors associated with blood donation practice}

Occupation is the only socio-demographic factor significantly associated with the blood donation practice; this might be due to the observed knowledge difference. Health professionals had almost two-fold donation practice than non-health professionals $(\mathrm{AOR}=1.62$; 95\% CI: 1.02, 2.57, $\mathrm{p}=0.042)$. As it is illustrated in the final logistic regression model participants who have no sufficient knowledge about blood donation were less likely to practice it than people who had sufficient knowledge (AOR $=0.82 ; 95 \% \mathrm{CI}$ : $0.54,1.27)$. Similarly respondents who had adequate attitude were more likely to practice blood donation than those who have no adequate attitude (AOR=1.67; 95\% CI: 0.71, 3.92). There were many reasons that the study participants mentioned why they were not donate blood (Figure 1). Based on the finding, the most common reasons that affect the blood donation practice of the participants were fear of anemia, they were not requested, and fear of sickness as frequently reported 81,77 and 40 times respectively.

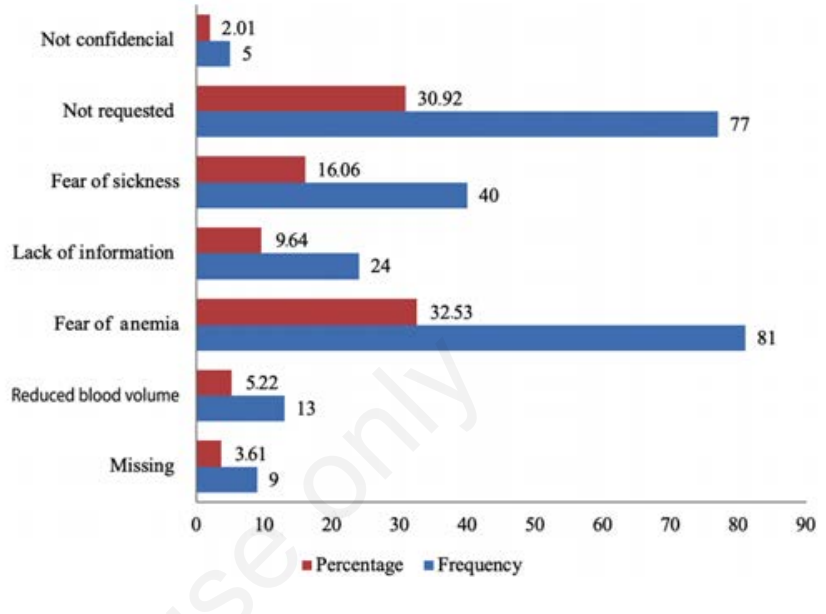

Figure 1. The main reason of participants for not donating blood.

Table 2. Socio-demographic factors associated with knowledge of blood donation.

\begin{tabular}{|c|c|c|}
\hline $\begin{array}{l}\text { Logistic regression predicting knowledge } \\
\text { Socio-demographic characteristics }\end{array}$ & Adjusted OR ( $95 \% \mathrm{CI})$ & p (Wald's test) \\
\hline $\begin{array}{l}\text { Sex } \\
\quad \text { Female } v s \text { male }\end{array}$ & $0.96(0.61,1.51)$ & 0.865 \\
\hline $\begin{array}{l}\text { Age group (ref. less than } 30 \text { ) } \\
30-40 \text { years } \\
40-50 \text { years } \\
\text { Above } 50\end{array}$ & $\begin{array}{l}0.6(0.36,1.01) \\
0.67(0.33,1.34) \\
0.52(0.14,1.98)\end{array}$ & $\begin{array}{l}0.053 \\
0.255 \\
0.337\end{array}$ \\
\hline $\begin{array}{l}\text { Education } \\
\quad \text { Degree } v \text { s Diploma }\end{array}$ & $1.5(0.9,2.49)$ & 0.120 \\
\hline $\begin{array}{l}\text { Occupation 2: } \\
\text { HP us NHP }\end{array}$ & $2.39(1.39,4.12)$ & 0.002 \\
\hline $\begin{array}{l}\text { Religion (ref. Orthodox) } \\
\text { Muslim } \\
\text { Protestant } \\
\text { Others }\end{array}$ & $\begin{array}{l}1.26(0.67,2.35) \\
1.31(0.78,2.2) \\
0.99(0.19,5.09)\end{array}$ & $\begin{array}{l}0.472 \\
0.303 \\
0.990\end{array}$ \\
\hline $\begin{array}{l}\text { Marital status (ref. Single) } \\
\text { Married } \\
\text { Divorced } \\
\text { Widowed }\end{array}$ & $\begin{array}{l}1.12(0.69,1.81) \\
0.48(0.13,1.69) \\
1.21(0.23,6.46)\end{array}$ & $\begin{array}{l}0.649 \\
0.250 \\
0.823\end{array}$ \\
\hline $\begin{array}{l}\text { Income (ref. less than 2000; \$66.7) } \\
\text { 2000-5000 (\$66.7-166.7) } \\
\text { Above } 5000(\$ 166.7)\end{array}$ & $\begin{array}{l}1.4(0.65,2.99) \\
1.86(0.69,5.03)\end{array}$ & $\begin{array}{l}0.387 \\
0.222\end{array}$ \\
\hline $\begin{array}{l}\text { Log-likelihood }=-249.3375 \\
\text { No. of observations }=394 \\
\text { aIC value }=528.675\end{array}$ & & \\
\hline
\end{tabular}

HP, health professional; NHP, non-health professional; aCI, adjusted confidence interval. 
Table 3. Factors associated with attitude of blood donation.

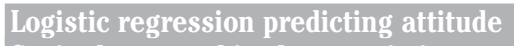

Sex

Female $v s$ male

$0.9912(0.381,2.5785)$

0.985

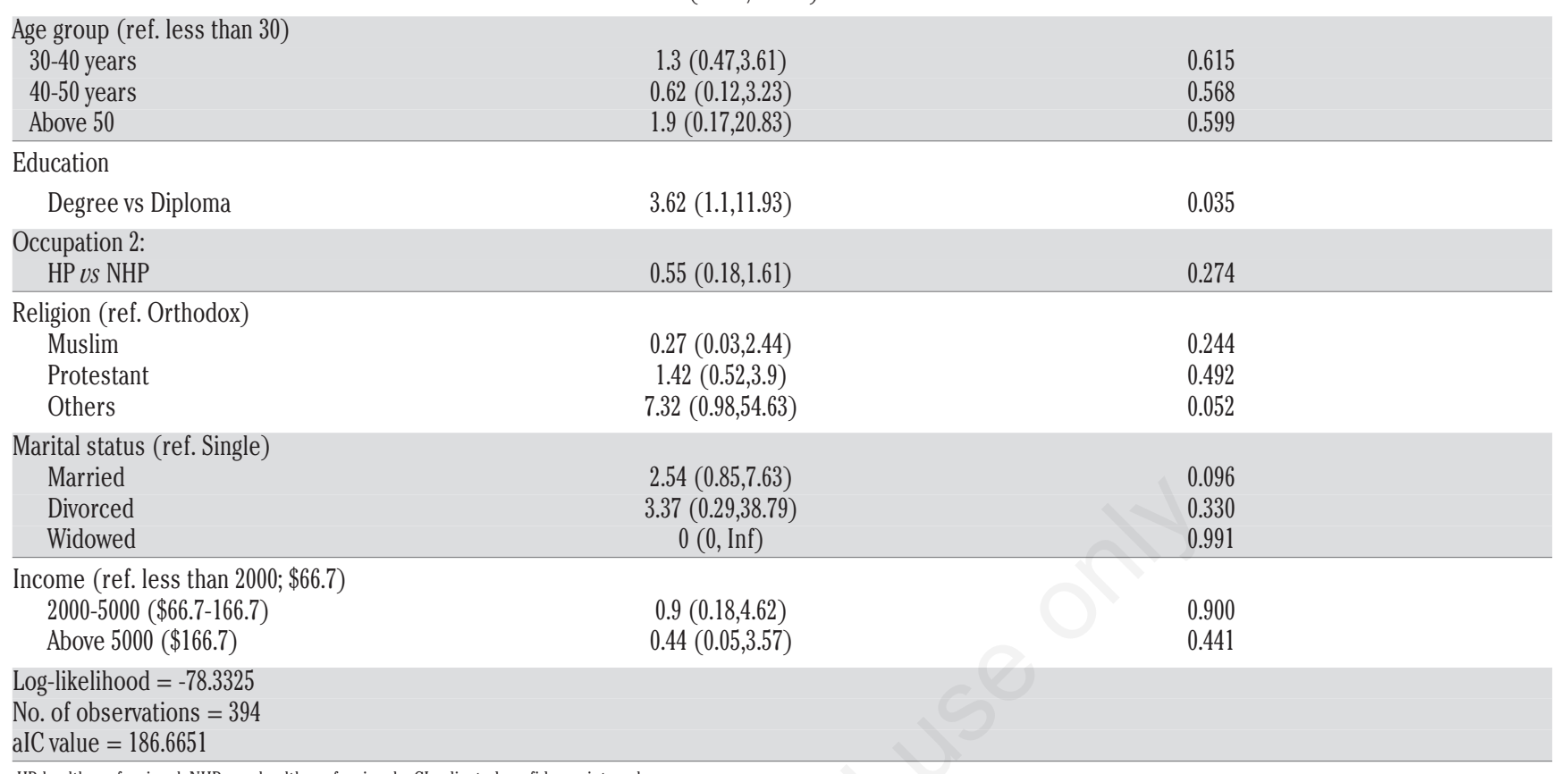

HP, health professional; NHP, non-health professional; aCl, adjusted confidence interval.

\section{History of donation practice}

This study indicates that only $142(36 \%)$ practiced the blood donation. Among this, more than half $(82,57.7 \%)$ of the individuals practiced blood donation at least once and $60(42.3 \%)$ of the participants have history of more than one blood donation practice. Regarding the history of the last blood donation, majority of 77 (54.6\%) the participants have more than a year. From all blood donors $102(72.3 \%)$ of the respondents were motivated to donate blood for charity. One hundred thirty-three (94.3\%) individuals were felt good after blood donation and not having been asked to donate blood were the major reason $88.6 \%$ for not participates in the blood donation frequently (Table 4 ).

\section{Discussion}

This study has been conducted to assess the level and factors of knowledge, attitude and practice of Hospital staffs, health professionals and non-health professionals. The knowledge of the participants ranged from 2 to 10 with a mean value of $7.22(\mathrm{SD}=1.56)$ which is comparable with results of the community-based study at Niger which describes there was overall good blood donation knowledge. ${ }^{20}$

Occupation was strongly associated with the blood donation knowledge of the participants. Health professional had better blood donation knowledge than non-health professionals with $(\mathrm{AOR}=2.39 ; 95 \% \mathrm{CI}: 1.39,4.12 ; \mathrm{p}=0.002)$. Even though there were no similar studies conducted among professionals and nonhealth professionals at the same time, results revealed that health professional are likely had good (82.6\%) and adequate knowledge about the benefits of blood donation ${ }^{1,2}$ compared to the result of community-based studies with percentage mean score of $58.07 \%$ in Saudi Arabia and 56.8\%, 56.5\%, and 43.5\% in Ethiopia. ${ }^{9-11,15}$
The study also revealed that degree and above level of education were one and half times more likely to have blood donation knowledge compared to Diploma level ( $\mathrm{AOR}=1.5$; 95\% CI: 0.9, 2.49). This was in line with the community-based study and a study among health professionals in Ethiopia. ${ }^{9,13}$ Against the above findings study conducted in Ethiopia among health professionals conclude that knowledge and attitude levels of the participants were not found to be significantly associated with socio-demographic parameters. ${ }^{1}$ This disagreement may be as the result of differences

Table 4. History of study participants about blood donation practice.

\begin{tabular}{lcc} 
History of donation practice & Frequency & Percentage \\
How many times you donate & & \\
$\quad$ Once & 82 & 57.7 \\
$\quad$ More than once & 60 & 42.3 \\
What was your last donation & & \\
$\quad$ Less than a year & 64 & 45.4 \\
$\quad$ More than a year & 77 & 54.6 \\
\hline What motivated you to donate & & \\
$\quad$ Charity & 102 & 72.3 \\
$\quad$ To save life & 22 & 15.6 \\
$\quad$ Morality & 17 & 12.1 \\
What do you feel after donation & & \\
$\quad$ Feel good & 133 & 94.3 \\
$\quad$ Nothing & 8 & 5.7 \\
Reason not to donate frequently & & \\
$\quad$ No privacy & 7 & 5.0 \\
$\quad$ I experience illness & 9 & 88.6 \\
$\quad$ Not requested & 124 & 100 \\
Total & 145 &
\end{tabular}


in study participants and location of the study. In logistic regression, the only independent socio-demographic variable strongly associated with the attitude of blood donors was the educational status of the participants with $(\mathrm{AOR}=3.62 ; 95 \% \mathrm{CI}: 1.1,11.93$; $\mathrm{p}=0.035$ ) (Table 5). This result was supported by a study conducted at Ethiopia which describes attending secondary and above education were found to be the independent predictors of positive attitude towards blood donation. ${ }^{9,11,13}$

The results of this study indicate that the blood donation practice was low with only $142(36 \%)$ of the participants donated blood which was lower from a finding of a study conducted among health professionals in Tigray Regional State with $47.8 \% .^{13}$ This deference may be because; our study considers both health professionals and non-professionals at the same time. However, the finding of the current study was higher from a result of a study conducted at Gondar Hospital only $33.2 \%$ of the participants donate blood. ${ }^{14}$ The likely causes for the differences between may be, our study site was at the center of the capital city in which participants may have better exposure, a good source of information and access to the blood donation centers.

The findings observed in this study lay in the middle of the finding of previous studies that have examined the blood donation practice among university students in different parts of Africa $55.4 \%, 45.8 \%, 30 \%, 22.9 \%, 12.5 \%$, and $9.74 \% 8,12,16,17,21,22$ and community-based studies $53.3 \%, 22.6 \%$ to $16.1 \%$. $9,11,15$ The study also further identified only $60(42.3 \%)$ repeated blood donor compared to $55 \%$ of in University students in Tanzania. ${ }^{19}$ This finding shows that the government and responsible bodies should give attention to design and implement an effective strategy to adhere repeated blood donors. In logistic regression, occupation was significant association to blood donation practice. The health professionals had almost two times more the odds of good practice on blood donation compared to non-professionals ( $\mathrm{ADR}=1.62 ; 95 \%$ CI: $1.02,2.57, \mathrm{p}=0.042$ ). Since there was no article which showed occupation as the factor of blood donation practice our findings could be used as the reference for future researchers. Respondents with adequate attitude have a good practice on blood donation compared to individuals who have an inadequate attitude $(\mathrm{AOR}=1.67 ; 95 \% \mathrm{CI}: 0.71,3.92)$. This finding was supported by a community-based study and facility-based studies among health professionals which described the attitude of the participants have a strong association with voluntary blood donation. ${ }^{13-15}$ Most of previous articles discussed different motivating factors, whereas our finding identified charity was the most common factor of the blood donation with $102(72.3 \%)$ of respondents were motivated to for charity. In the contrast, lack of request was the major reason that causes $88.6 \%$ of respondents not to donate blood frequently. This finding was supported by similar study reported that majority of the participants did not donate blood as they have not been approached. ${ }^{1}$

Table 5. Logistic regression predicting practice of blood donation.

$\begin{array}{lcc}\text { Logistic regression predicting practice } & \\ \begin{array}{l}\text { Socio-demographic } \\ \text { characteristics }\end{array} & \text { Adjusted OR p (Wald's } \\ & (95 \% \mathrm{CI}) & \text { test) }\end{array}$

Occupation

Health $v s$ non-health professional

$1.62(1.02,2.57) \quad 0.042$

Knowledge

Sufficient vs insufficient

$0.82(0.54,1.27) \quad 0.376$

Attitude

Adequate $v$ inadequate

$1.67(0.71,3.92) \quad 0.237$

\section{Limitation of the study}

The generalizability of these results is subject to certain limitations. For instance, this was a cross-sectional study which may not show the cause-and-effect relationship. It was a single-center study among hospital staffs, which is placed in the capital city of the country with better exposure, information, and access to the center of voluntary blood donation.

\section{Recommendation and conclusions}

According to this study, there was low blood donation with only $142(36 \%)$ partisans practiced in their lifetime. Only $60(42.3 \%)$ of the donors have a history of more than one donation practice. Occupation was the only significantly factor; health professionals had almost two-fold donation practice than non-health professionals. Fear of anemia and not approaching to donate was the leading reasons for non-donors.

This information can be used by Health Bureau and the RedCross societies in Ethiopia to develop targeted interventions aimed at mobilizing hospital staffs and develop accessible blood donation centers to reverse the effect of inadequate blood supply system in Ethiopia.

Correspondence: Melese Yeshanbaw Teferi, Armauer Hansen Research Institute (AHRI), Addis Ababa, Ethiopia.

Tel.+251912212300. E-mail: myeshambaw@gmail.com

Key words: Knowledge; attitude; practice; voluntary blood donation; Ethiopia.

Contributions: All authors participated in conducting in the research and manuscript writing. CM, study concept and design; MY, HT, analysis, interpretation drafting the article or revising it critically for important intellectual content; SG, SA, EH, participated in the development of the data collection tools. All authors participated and approve the final version to be published.

Conflict of interest: The authors declare that they have no competing interests, and all authors confirm accuracy.

Acknowledgments: The authors are grateful to the ALERT Hospital staff for giving an opportunity for the research and unreserved cooperation in making this study to be a fruitful work.

Ethics approval and consent to participate: Before the start of the data collection process ethical clearance was obtained from AHRI ethical committee. Following the approval of the proposal, a letter will be submitted to ALERT hospital director. Information on the research was provided on participant sheet and written informed consent was also taken from each participant using the informed consent sheet. Any information regarding subjects was kept confidential.

Availability of data and materials: All data generated or analyzed during this study are included in this published article.

Received for publication: 15 July 2020.

Accepted for publication: 27 November 2020.

oCopyright: the Author(s), 2021

Licensee PAGEPress, Italy

Journal of Public Health Research 2021;10:1860

doi:10.4081/jphr.2020.1860

This work is licensed under a Creative Commons Attribution

NonCommercial 4.0 License (CC BY-NC 4.0). 


\section{References}

1. Malako D, Yoseph F, Bekele ML. Assessment of knowledge, attitude and practice and associated factors of blood donation among health care workers in Ethiopia: a cross-sectional study. BMC Hematol 2019;19:10.

2. Bilal M, Haseeb A, Zahid I, et al. Knowledge, attitudes and perceptions among non-blood donor female health care professionals. Global J Health Sci 2016;8:203.

3. WHO, International Water Association. Global Status Report on Water Safety Plans: A review of proactive risk assessment and risk management practices to ensure the safety of drinking-water. 2017. Available from: https://www.who.int/water_ sanitation_health/publications/global-status-report-on-watersafety-plans/en/

4. Custer B, Zou S, Glynn SA, et al. Addressing gaps in international blood availability and transfusion safety in low-and middle-income countries: a NHLBI workshop. Transfusion 2018;58:1307-17.

5. Nureye D, Tekalign E. Opportunities and challenges of blood donation and blood therapy in Ethiopia. Health Sci 2019;8: $122-7$.

6. Zanin TZ, Hersey DP, Cone DC, Agrawal P. Tapping into a vital resource: Understanding the motivators and barriers to blood donation in Sub-Saharan Africa. Afr J Emerg Med 2016;6:70-9.

7. Asamoah-Akuoko L, Hassall OW, Bates I, Ullum H. Blood donors' perceptions, motivators and deterrents in Sub-Saharan Africa-a scoping review of evidence. $\mathrm{Br} \mathrm{J}$ Haematol 2017;177:864-77.

8. Melku M, Asrie F, Shiferaw E, et al. Knowledge, attitude and practice regarding blood donation among graduating undergraduate health science students at the University of Gondar, Northwest Ethiopia. Ethiopian journal of health sciences. 2018;28(5)

9. Urgesa K, Hassen N, Seyoum A. Knowledge, attitude, and practice regarding voluntary blood donation among adult residents of Harar town, Eastern Ethiopia: a community-based study. J Blood Med 2017;8:13.

10. Melku M, Terefe B, Asrie F, et al. Knowledge, attitude, and practice of adult population towards blood donation in Gondar Town, Northwest Ethiopia: a community based cross-sectional study. J Blood Transfus 2016;2016: 949862.
11. Jemberu YA, Esmael A, Ahmed KY. Knowledge, attitude and practice towards blood donation and associated factors among adults in Debre Markos town, Northwest Ethiopia. BMC Hematol 2016;16:23.

12. Majdabadi HA, Kahouei M, Taslimi S, Langari M. Awareness of and attitude towards blood donation in students at the Semnan University of Medical Sciences. Electr Phys 2018;10:6821.

13. Tadesse T, Berhane T, Abraha TH, et al. Blood donation practice and associated factors among health professionals in Tigray regional state public hospitals, northern Ethiopia. BMC Res Notes 2018;11:677.

14. Arage G, Ibrahim S, Adimasu E. Blood donation practice and its associated factors among health professionals of University of Gondar Hospital, Northwest Ethiopia: a cross sectional study. BMC Res Notes 2017;10:1-6.

15. Abolfotouh MA, Al-Assiri MH, Al-Omani M, et al. Public awareness of blood donation in Central Saudi Arabia. Int J General Med 2014;7:401.

16. Alfouzan N. Knowledge, attitudes, and motivations towards blood donation among King Abdulaziz Medical City population. Int J Family Med 2014;2014:539670.

17. Raghuwanshi B, PeHlAjANI NK, Sinha MK. Voluntary blood donation among students-a cross-sectional study on knowledge and practice vs. attitude. J Clin Diagn Res 2016;10:EC18.

18. Tariq S, Jawed S. Knowledge and attitude of blood donation among female medical students in Faisalabad. JPMA. J Pak Med Assoc 2018;68:65-70.

19. Elias E, Mauka W, Philemon RN, et al. Knowledge, attitudes, practices, and factors associated with voluntary blood donation among university students in Kilimanjaro, Tanzania. J Blood Transfus 2016;2016:8546803.

20. Ehimen FA, Osagiede EF, Abah SO, et al. Assessment of the knowledge, attitude and practice of voluntary non-remunerated blood donation among residents of Ekpoma, a peri-urban community in Edo State. Niger J Med 2016;25:348-57.

21. Chauhan R, Kumar R, Thakur S. A study to assess the knowledge, attitude, and practices about blood donation among medical students of a medical college in North India. J Family Med Prim Care 2018;7:693.

22. Nwogoh B, Aigberadion U, Nwannadi AI. Knowledge, attitude, and practice of voluntary blood donation among healthcare workers at the University of Benin Teaching Hospital, Benin City, Nigeria. J Blood Transfus 2013;2013: 797830. 